\title{
In Vitro Conditions for the Self-Polymerization of the Microtubule-Associated Protein, Tau Factor
}

\author{
Esteban MONTEJO de GARCINI and Jesús AVILA \\ Centro de Biología Molecular (CSIC-UAM), Universidad Autónoma, \\ Canto Blanco, 28049 Madrid, Spain
}

Received for publication, May 15, 1987

\begin{abstract}
One of the microtubule associated proteins, tau factor, that appears associated to the paired helical filaments of Alzheimer's disease presents, by itself, after urea treatment, the ability of polymerizing in vitro as tested by immunoelectronmicroscopy. These polymers resemble in their width and appearance those of the paired helical filaments. The conditions required for this assembly have been studied and determined the protein concentration needed, the influence of salt concentration and $\mathrm{pH}$ as well as the possible modifications (deamination, acylation) which may be implied in such in vitro polymerization.
\end{abstract}

Microtubule associated protein tau factor binds to polymerized tubulin ( $l$, and may self-assemble into filaments (2), but also is present as a main component of the paired helical filaments present in Alzheimer's disease (3-8). Since recently it has been indicated that tau factor is able to self assemble into filaments (2) a working hypothesis could suggest that tau protein is the one that builds the backbone of PHF. It was found that tau factor is only able to polymerize after an urea treatment which may result among other modifications in a deamination of the protein (2).

On the other hand, it has been proposed a relation between Alzheimer's disease filaments and amyloid fibrils $(9-11)$, probably assembled upon modification of a precursor protein (11). Several types of modifications of different proteins may result in their polymerization into fibrils. Those modifications may involve treatments at low salt (12), low pH (13), or with some enzymes $(14,15)$. In this study we analyze how those conditions affect to the polymerization in vitro of tau factor.

\section{MATERIALS AND METHODS}

Materials - Transglutaminase and glutaminases grade II, V, and VI were obtained from Sigma. Protein A from Staphylococcus aureus was purchased from Pharmacia. V8 S. aureus protease was from Miles.

Protein Preparation-Tau was purified from porcine brain microtubules as described (16). The protein was analyzed by polyacrylamide gel electrophoresis by the method of Laemmli (17) and protein concentration was measured by the method of Lowry et al. (18). Paired helical filaments were purified from human brains as described (19).

Urea Treatment-Incubation of tau protein with $8 \mathrm{M}$ urea was carried out at room temperature for at least 3 days. After that, it was dialyzed against buffer A $(0.1 \mathrm{M}$ MES, pH $6.61 \mathrm{mM}$ $\mathrm{MgCl}_{2}, 2 \mathrm{mM}$ EGTA) for 1 day. Then, the pro- 
tein was incubated for polymerization at $37^{\circ} \mathrm{C}$ for $30 \mathrm{~min}$.

Electron Microscopy-Sample preparations were carried out by placing a drop of the assembly mixture onto a carbon-collodion electron microscopy grid. The protein was then stained with $1 \%$ uranyl acetate and observed in an electron microscope JEOL 100B. The magnification (microscopy field) was that indicated at the legends of the figures.

The assays for immunoelectronmicroscopy were carried out as described (20) by incubating the sample placed on the grid with a monospecific tau antibody (2l), followed by incubation with protein A conjugated with colloidal gold particles (20), as previously indicated. The samples were stained and visualized as indicated above. preparations of glutaminase (grade II, V, or VI) were carried out at $37^{\circ} \mathrm{C}$ for $30 \mathrm{~min}$. Acetate buffer $\mathrm{pH} 4.9$ or buffer A was used for glutaminase grades II or V and Tris buffer pH 9.0 for glutaminase grade VI. Samples were then incubated for polymerization at $37^{\circ} \mathrm{C}$ for $30 \mathrm{~min}$. Currently the concentrations used for glutaminase were 1-10 units $/ \mathrm{ml}$ and the one for tau protein was $1-2 \mathrm{mg} /$ $\mathrm{ml}$.

Transglutaminase treatment was carried out using tritiated putrescine as described (22). The result of such treatment was followed by gel filtration on Sepharose $4 \mathrm{~B}-\mathrm{CL}$ and the radioactivity associated to tau protein was determined.

Peptide Maps-S. aureus V8 protease peptide maps were carried out as described (23) with protein iodinated as previously indicated (21).

Enzymatic Assays-Incubations with different

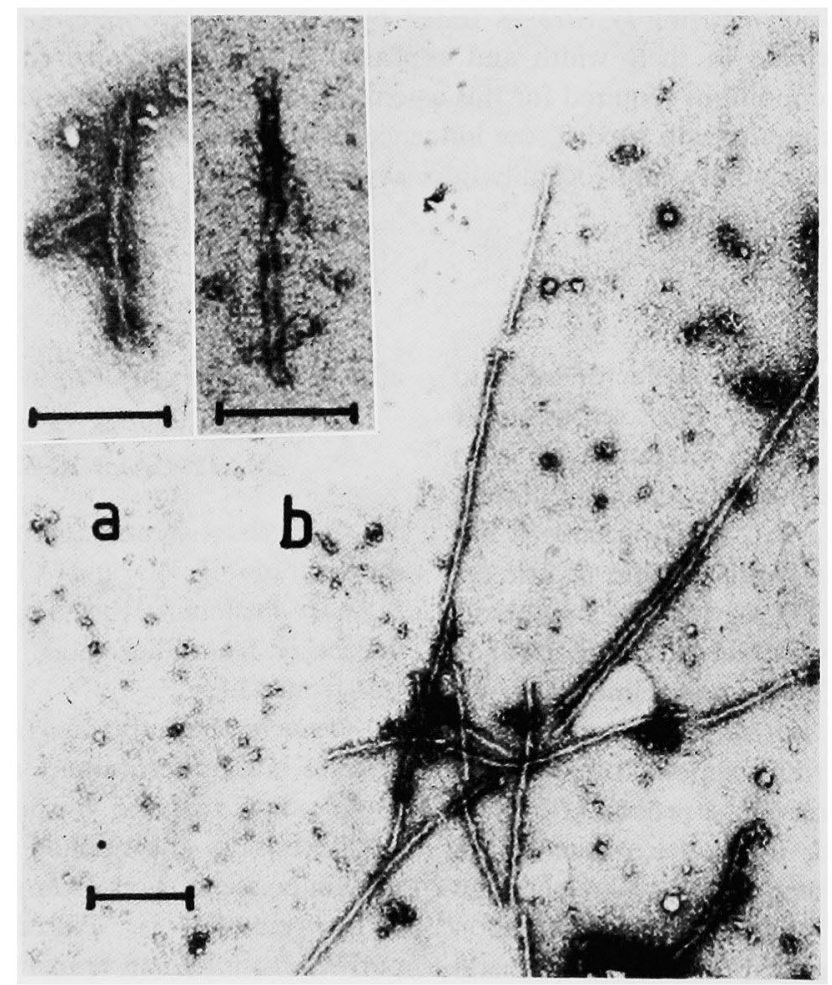

Fig. 1. Polymers of tau factor. Modified tau factor was prepared for polymerization and electron microscopy as indicated in "MATERIALS AND METHODS." The polymers obtained are shown. The inset shows the detail of one PHF purified as indicated in the text (a) and a tau filament obtained by urea treatment (b). Bars indicate $0.2 \mu \mathrm{m}$. 


\section{RESULTS AND DISCUSSION}

Microtubule associated protein tau factor may self-assemble into filaments upon urea treatment (2). This treatment may result in a deamination of glutamine or asparagine residues (24).

Tau protein was treated with urea for different times and assayed for polymerization. At least an incubation of $60 \mathrm{~h}$ in the presence of urea was required to find tau polymers. Such treatment resulting in the aggregation of the protein, may be a consequence of conformational changes resulting in protein denaturation as suggested for amyloid substance (25). However, polymerization of tau factor was not observed upon treatment with another denaturing agent, guanidine hydrochloride, in conditions similar to those used for urea. Thus, a modification induced by urea may

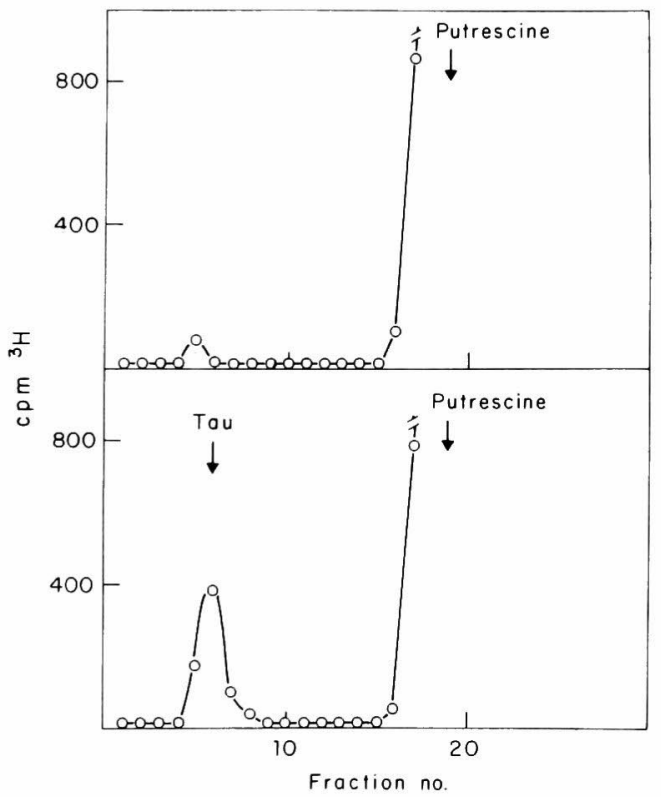

Fig. 2. Transglutaminase treatment of urea treated and untreated tau. The protein was incubated with transglutaminase as described in " MATERIALS AND METHODS" and the mixture was chromatographed on a Sepharose $4 \mathrm{~B}-\mathrm{CL}$ column previously calibrated with tau protein. Radioactivity associated with tau protein was determined. The arrows indicate the positions of tau factor and putrescine. Upper panel shows the result for untreated protein and the lower one for urea treated tau. promote tau assembly into filaments showing a structure related to the paired helical filaments found in the brain of Alzheimer's disease patients (Fig. 1).

Long incubation with urea may result in a) a slight increase in the $\mathrm{pH}$, b) deamination of glutamine or asparagine residues (24), or c) protein carbamylation. An increase in the $\mathrm{pH}$ resulting in deprotonation of clustered histidines may result in protein aggregation. Previously (2) it was suggested a deamination of tau upon urea treatment since a higher proportion of acidic residues is available to $S$. aureus V8 protease (an enzyme which cleaves preferentially acidic residues) (26). Another suggestion indicating that deamination may also take place is that showing that the modified protein is a better substrate (Fig. 2)

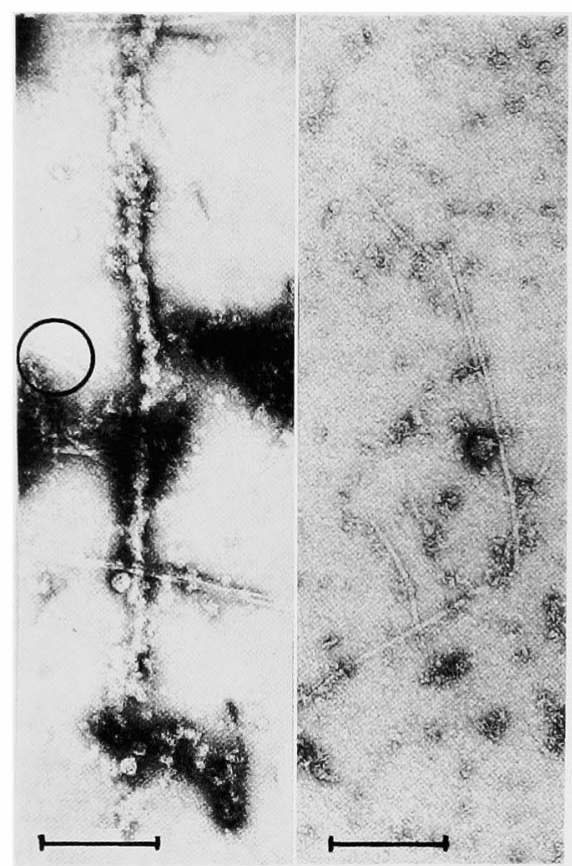

Fig. 3. Effect of glutaminase on tau factor. Tau factor was treated with different preparations of glutaminase as indicated in "MATERIALS AND METHODS." Figure (left) shows the result of the treatment of tau with the commercial preparation glutaminase grade II. It resulted in the appearance of some wide filaments together with other filaments (see circle) present in the glutaminase preparation. Glutaminase filaments may be also observed (right). Bars indicate $0.2 \mu \mathrm{m}$. 
for transglutaminase, that also requires the presence of glutamic residues, than the unmodified tau factor. To test whether or not deamination was the main reason for self-assembly, different commercial preparations of glutaminase were used. These preparations differ in their degree of purification. Figure 3 shows that, in the presence of glutaminase, some filaments were found, although no increase in the number of polymers was found when more purified glutaminase preparations were used. In fact, by using the preparation grade VI almost no filaments were obtained and only partially assembled structures were found (see below). Also, in some glutaminase preparations (grade

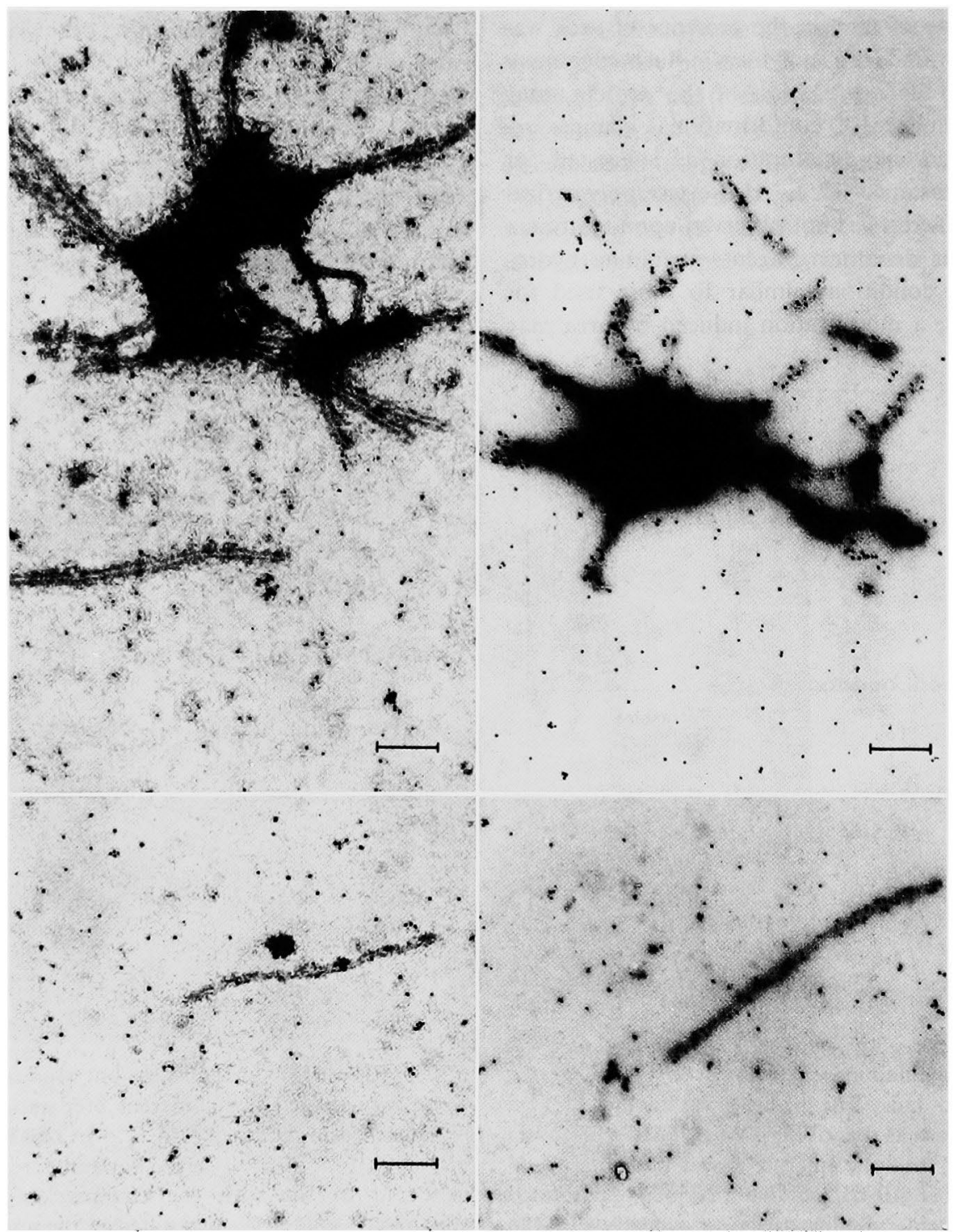

Fig. 4. Immunoelectronmicroscopy staining of tau protein polymers. Tau protein was prepared for electron microscopy as described in "MATERIALS AND METHODS." In the absence of antitau antibodies, the staining was absent from the polymers (left panels) but in the presence of antibody the polymers were stained (right panels). Bars indicate $0.2 \mu \mathrm{m}$. 
II, some lots of grade V but never in grade VI preparations) we found the existence of filamentous structures which could confuse the observation of tau filaments when that protein is present. Glutaminase filaments present a narrower (three to six times) diameter and a more brilliant staining (Fig. 3), than tau polymers. To test that tau polymers indeed exist, an immunolabeling of them by using antibodies coupled with protein A-gold was performed. Figure 4 shows a high staining of the polymers when monospecific antibodies against tau protein were used but not when other sera were tested. In Fig. 4 is also shown that the high proportion of tau antibodies bound to the filaments affect to their morphology. The use of

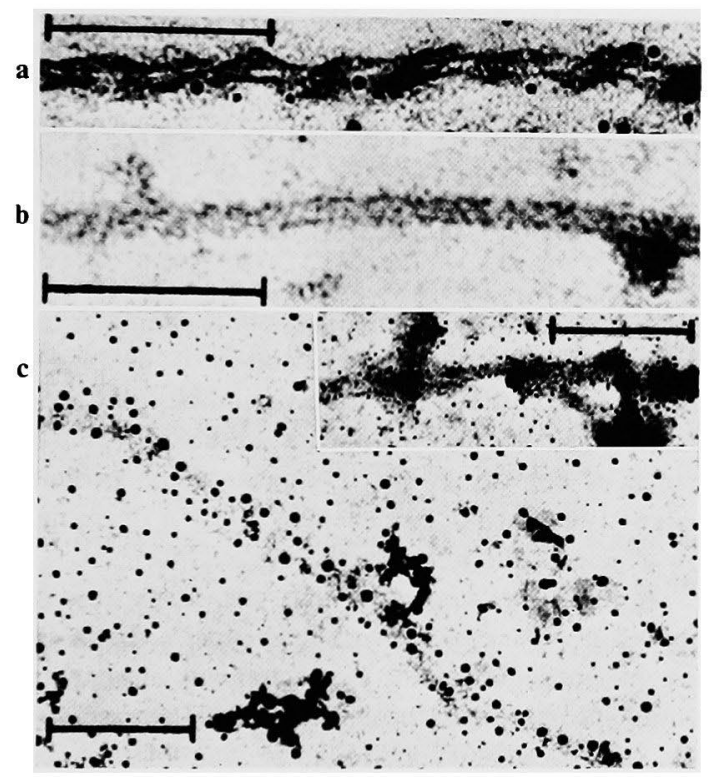

Fig. 5. Immunoelectronmicroscopy staining of tau polymers found in the presence of glutaminase. Tau was treated with $8 \mathrm{M}$ urea (a) or incubated with glutaminase (grade II) (b) as indicated in " MATERIALS AND METHODS " and the polymerized protein visualized under the electron microscope. Also, tau protein was incubated with glutaminase (grade VI) as indicated in " MATERIALS AND METHODS" and processed for immunoelectronmicroscopy as indicated above (c). Few filaments were found but they showed a higher labeling than that found in the background. Inset shows a tau polymer (found in the presence of glutaminase, grade V) labeled with gold and surrounded by those filaments found in glutaminase preparations. Bars indicate $0.2 \mu \mathrm{m}$. immunolabeling techniques also allows to differentiate tau polymers of those found in glutaminase preparations of bacterial origin (Fig. 5). Figure 5 shows the polymers with appear in the presence of glutaminase of different origins (grades II, V, or VI). In each case, less regular polymers than those observed upon urea treatment were found. When glutaminase grades II, V, or VI were used mainly partially assembled structures were found and only urea treatment yields polymers resembling paired helical filaments.

Furthermore, in Fig. 5 it is shown that the structure of a tau filament which resembles that of paired helical filaments found in Alzheimer's disease. (See also Fig. 6 and compare the morphology of those filaments with that of the PHF shown in Ref. 27.)

As indicated above a minimum time of urea treatment is needed to obtain not only tau polymers but also structures resembling paired helical filaments. In our conditions too short ( 1 day) or too large treatments could modify the structure shown in Fig. 5 or 6.

When tau polymers, obtained as indicated in " MATERIALS AND METHODS," were measured at their widest and narrowest diameter and calculated the periodicity of them, we found values for the morphology of the polymers similar to those indicated for paired helical filaments found

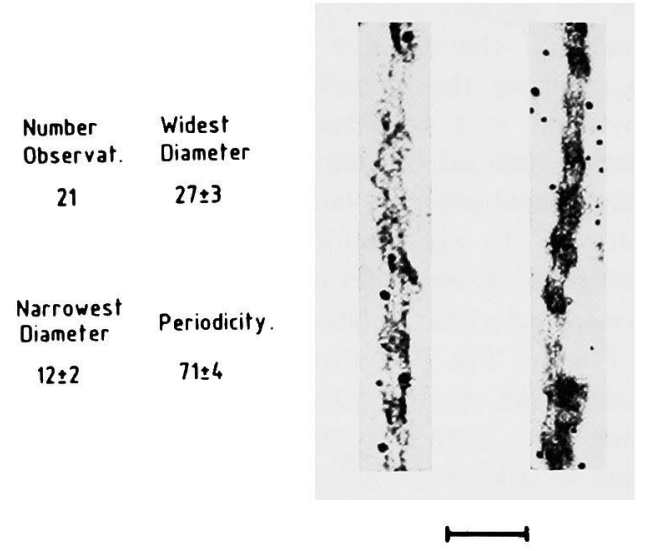

Fig. 6. Tau polymers dimensions. Tau polymers were stained for electron microscopy as indicated above and only the polymers well preserved during the treatment were measured and their dimensions measured. The figure also shows two of the measured polymers. Bar indicates $0.1 \mu \mathrm{m}$. Table dimensions are in nanometers. 
in Alzheimer's disease (27).

The above results suggest that deamination of glutamine residues could take place during the urea treatment, needed for tau assembly but it is not the main reason for that polymerization since a) there is not a relationship between glutaminase treatment and number of filaments found, b) fewer filaments were always found after incubation with glutaminase than after urea treatment, and c) the morphology of the polymers assembled after incubation with glutaminase did not resemble that of paired helical filaments at difference than that of the polymers assembled after urea treatment. Thus, other factors may also favor the assembly of tau.

Solutions of urea slowly form ammonium cyanate (28) in small amounts and it was demonstrated that the cyanate present in concentrated urea solutions may react very rapidly with thiol groups and more slowly with amino groups of proteins $(29,30)$. Previously it was found that modification of thiol groups did not affect to the assembly of tau (2). Moreover, the urea transformation of tau requires longer periods than those required for carbamylation of thiol groups and similar to those needed for carbamylation of amino groups (29). Such carbamylation indeed took place in our conditions as determined by titration of available lysine residues using acetic anhydride (data not shown). This result suggests that conformational changes due to carbamylation may also facilitate the assembly of tau. Since carbamylation is a modification in lysines similar to that produced by anhydrides, we have tested whether incubation of tau with acetic anhydride results in its aggregation into polymers. The result of such an experiment indicated that no polymers were found (data not shown).

Finally, Fig. 7 shows the effect of protein concentration on the polymerization capacity of modified tau factor. It shows that a tau concentration of at least $0.5 \mathrm{mg} / \mathrm{ml}$ is required to visualize one filament per microscopy field (see "MATERIALS AND METHODS"). Other factors such as salt (from 0.1 to $1 \mathrm{M} \mathrm{NaCl}$ ) or the $\mathrm{pH}$ (from $\mathrm{pH}$ 5 to 8 ) did not affect to the assembly of urea treated tau.

The above results suggest that tau is able to polymerize into filaments resembling those found in Alzheimer's disease. In Figs. 5 and 6 it is

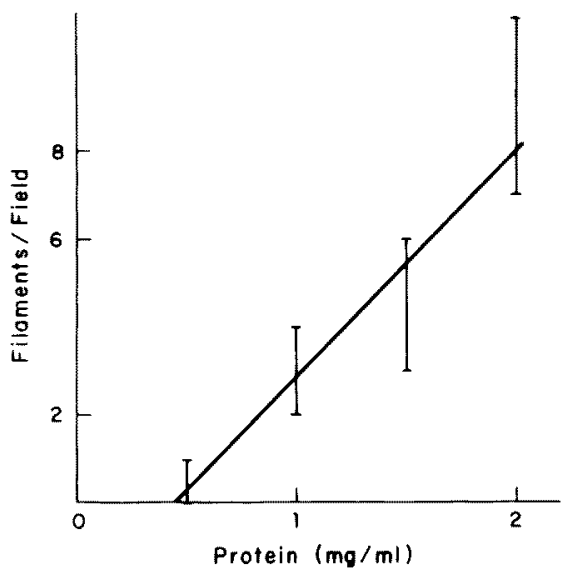

Fig. 7. Effect of protein concentration on the appearance of tau polymers. The protein was modified and incubated for polymerization as described in "MATERIALS AND METHODS." Using different concentrations of protein the number of filaments appearing per field unit was determined and represented. The average of four different experiments at each protein concentration is indicated by bars.

found that such polymers present a diameter of about $25 \mathrm{~nm}$ in their widest and it is gradually reduced to about $10 \mathrm{~nm}$ with a periodicity of about $70 \mathrm{~nm}$. Tau assembly appears to be the consequence of conformational changes of the protein mediated in part but not exclusively by a deamination which results in its partial aggregation.

It has been suggested that the formation of amyloid fibrillary or that of Alzheimer's filaments may be consequence of a mechanism similar to that of protein denaturation (25). However, we have not found effects similar to that of urea by using other denaturing agents such as guanidine hydrochloride or by using other agents such as glycerol known by its capacity of precipitating tau protein (3l). Protein polymerization upon urea incubation appears to be specific in heat resistant microtubule associated proteins, for tau; since MAP $_{2}$ did not assemble after such a treatment (M.A. Hernández, unpublished results).

The changes resulting in the polymerization of tau factor could also be due to posttranslational modifications such as phosphorylation $(7,32)$ that could modify the conformation of tau in a similar way to that of urea treatment. Those types of posttranslational modification may be the cause 
for the in vivo formation of some of the filamentous structures found in Alzheimer's disease. However, the conditions indicated in this paper to produce tau polymers may be of great utility for the in vitro studies and clearly show that tau has in itself the ability for self-assembling.

\section{REFERENCES}

1. Weingarten, M.D., Lockwood, A.H., Hwo, S.Y., \& Kirschner, M.W. (1975) Proc. Natl. Acad. Sci. U.S. 72, 1858-1862

2. Montejo de Garcini, E., Serrano, L., \& Avila, J. (1986) Biochem. Biophys. Res. Commun. 141, 790796

3. Kidd, M. (1963) Nature 197, 192-193

4. Grundke-Iqbal, I., Iqbal, K., Quinlan, M., Tung, Y.C., Zaidi, M., \& Wisniewski, H.M. (1986) $J$. Biochem. 261, 6084-6089

5. Wood, J.G., Mirra, S.S., Pollock, N.J., \& Binder, L.I. (1986) Proc. Natl. Acad. Sci. U.S. 83, 4040-4043

6. Kosik, K., Joachim, C.L., \& Selkoe, D. (1986) Proc. Natl. Acad. Sci. U.S. 83, $4044-4048$

7. Grundke-Iqbal, I., Iqbal, K., Tung, Y.C., Quinlan, M., Wisniewski, H.M., \& Binder, L.I. (1986) Proc. Natl. Acad. Sci. U.S. 83, 4913-4917

8. Nukina, N. \& Ihara, Y. (1986) J. Biochem. 99, 1541-1544

9. Castaño, E.M., Ghiso, J., Prelli, F., Gorevic, P.D., Migheli, A., \& Frangione, B. (1986) Biochem. Biophys. Res. Commun. 141, 782-789

10. Master, C.L., Multhaup, G., Sim, G., Pottgiesser, J., Martins, R.N., \& Beyreuther, K. (1985) EMBO J. 4, 2757-2763

11. Glenner, G.C. (1980) N. Engl. J. Med. 302, 12831292

12. Connors, H.L., Shirahama, T., Skinner, M., Fenver, A., \& Cohen, A.S. (1985) Biochem. Biophys. Res. Commun. 131, 1063-1068

13. Glenner, G.G., Eanes, E.C., Bladen, H.A., Linke, R.P., \& Temine, J.D. (1974) J. Histochem. Cyto- chem. 22, 1142-1158

14. Solomon, A. \& McLaughlin, C.L. (1969) J. Biol. Chem. 244, 3393-3404

15. Glenner, G.G., Ein, D., Eanes, E.C., Bladen, H.A., Ward, T., \& Page, D.L. (1971) Science 174, 712714

16. Herzog, W. \& Weber, K. (1978) Eur. J. Biochem. 92, $1-8$

17. Laemmli, U.K. (1970) Nature 227, 680-685

18. Lowry, O.H., Rosebrough, N.J., Farr, A.L., \& Randall, R.J. (1951) J. Biol. Chem. 193, 265-275

19. Iqbal, K., Zaidi, T., Thompson, C.K., Merz, P.A., \& Wisniewski, H.M. (1984) Acta Neuropathol. 62, 167-177

20. De la Torre, J., Carrascosa, J.L., \& Avila, J. (1986) Eur. J. Cell. Biol. 40, 233-237

21. Montejo de Garcini, E., Diez, J.C., \& Avila, J. (1986) Biochim. Biophys. Acta 881, 456-461

22. Maccioni, R.B. \& Seeds, N. (1986) Mol. Cell. Biochem. 69, 161-168

23. Cleveland, D.W., Fisher, S.G., Kirschner, R.W., \& Laemmli, U.K. (1977) J. Biol. Chem. 252, 11021106

24. Marshall, R.C. \& Inglis, A.S. (1986) in Practical Protein Chemistry (Darbre, A., ed.) pp. 2-66, John Wiley \& Sons, Chichester

25. Delacourte, A. \& Defossez, A. (1986) J. Neurol. Sci. 76, 173-186

26. Houmard, J. \& Drapeau, G.R. (1986) Proc. Natl. Acad. Sci. U.S. 69, 3506-3509

27. Wisniewski, H.M., Narang, H.K., \& Terry, R.D. (1976) J. Neurol. Sci. 27, 173-181

28. Cole, E.G. \& Mecham, D.K. (1966) Anal. Biochem. 14, 215-222

29. Stark, G.R., Stein, W.H., \& Moore, D. (1960) J. Biol. Chem. 235, 3177-3181

30. Cole, R.D. (1961) J. Biol. Chem. 236, 2670-2671

31. Lindwall, G. \& Cole, R.D. (1985) J. Biol. Chem. 259, 12241-12245

32. Ihara, Y., Nukina, N., Miura, R., \& Ogawara, M. (1986) J. Biochem. 99, 1807-1810 